\title{
Domestic impact of tuberculosis screening among new immigrants to Ontario, Canada
}

\author{
Kamran Khan MD MPH, M. Mustafa Hirji MD MPH, Jennifer Miniota MSc, Wei Hu MSA, Jun Wang MSc, \\ Michael Gardam MD MSc, Sameer Rawal MD, Edward Ellis MD, Angie Chan MSc, Maria I. Creatore PhD, \\ Elizabeth Rea MD
}

See also www.cmaj.ca/lookup/doi/10.1503/cmaj.150317

\begin{abstract}
Background: All Canadian immigrants undergo screening for tuberculosis (TB) before immigration, and selected immigrants must undergo postimmigration surveillance for the disease. We sought to quantify the domestic health impact of screening for TB in all new immigrants and to identify mechanisms to enhance effectiveness and efficiency of this screening.

Methods: We linked preimmigration medical examination records from 944375 immigrants who settled in Ontario between 2002 and 2011 to active TB reporting data in Ontario between 2002 and 2011. Using a retrospective cohort study design, we measured birth country-specific rates of active TB detected through preimmigration screening and postimmigration surveillance. We then quantified the proportion of active TB cases among residents of Ontario born abroad that were detected through postimmigration surveillance. Using Cox regression, we identified independent predictors of active TB postimmigration.
\end{abstract}

Results: Immigrants from 6 countries accounted for $87.3 \%$ of active TB cases detected through preimmigration screening, and 10 countries accounted for $80.4 \%$ of cases detected through postimmigration surveillance. Immigrants from countries with a TB (all-sites) incidence rate of less than 30 cases per 100000 persons resulted in pre- and postimmigration detection of 2.4 and 0.9 cases per 100000 immigrants, respectively. Postimmigration surveillance detected $2.6 \%$ of active TB cases in Ontario residents born abroad, and TB was detected a median of 18 days earlier in those undergoing surveillance than in those who were not referred to surveillance or who did not comply. Predictors of active TB postimmigration included radiographic markers of old TB, birth country, immigration category, location of application for residency, immune status and age.

Interpretation: Universal screening for TB in new immigrants has a modest impact on the domestic burden of active TB and is highly inefficient. Focusing preimmigration screening in countries with high incidence rates and revising criteria for postimmigration surveillance could increase the effectiveness and efficiency of screening.
$\mathrm{S}$ hifting global migration patterns have transformed the epidemiology of tuberculosis (TB) in the countries that receive large numbers of immigrants. ${ }^{1-3}$ In Canada and the United States, two-thirds of all TB now occurs in patients born abroad, who comprise just one-fifth and one-eighth of the national populations, respectively. ${ }^{4-7}$ Each year, about 400000 prospective immigrants to Canada undergo screening for active TB, of which about 250000 settle in Canada. ${ }^{8} 9$ These preimmigration medical examinations, coupled with postimmigration surveillance of selected immigrants deemed to be at high-risk for the devel- opment of active $\mathrm{TB},{ }^{10}$ require the coordinated efforts of federal, provincial or territorial, and local health authorities, as well as medical providers and the immigrants themselves. Despite the complexity and cost of this screening program, its domestic impact on active TB in patients born abroad is poorly understood. ${ }^{11-16}$

Ontario is Canada's largest province (population 13 million), the destination of $40 \%$ of all new Canadian immigrants and the source of $50 \%$ of Canada's TB cases in patients born abroad. ${ }^{17-19}$ All applicants seeking permanent residency in Canada must undergo preimmigration medical screening, which can be performed overseas or within Can-
Competing interests: None declared.

This article has been peer reviewed.

Accepted: Aug. 5, 2015

Online: Sep. 28, 2015

Correspondence to:

Kamran Khan,

khank@smh.ca

CMAJ 2015. DOI:10.1503/ cmaj.150011 
ada for those already in the country. The examination comprises a history, a physical examination, a chest radiograph and testing for HIV, syphilis and chronic kidney disease. Applicants with radiographic findings of TB undergo further testing, with 3 sputum mycobacterial smears and cultures.

Applicants in whom active TB is diagnosed must complete treatment before being granted permanent residency. Applicants without active TB but who have a self-reported history of TB or radiographic markers of old TB are referred by immigration officials to public health authorities in their destination province or territory for medical assessment within 30 days of arrival. Noncompliance with postimmigration surveillance does not impact permanent residency status but is a prerequisite for Canadian citizenship. At the discretion of the medical provider (i.e., there are no national standards), patients may undergo testing for latent TB infection and be offered treatment or monitored for active TB, typically for up to 2 years (see Appendix 1, available at www.cmaj.ca/ lookup/suppl/doi:10.1503/cmaj.150011/-/DC1).

We sought to assess the effectiveness and efficiency of the current practice of screening new immigrants for TB before and after immigration, while evaluating the overall impact of immigration-related TB screening on the domestic burden of disease in Canada.

\section{Methods}

\section{Study cohort}

We created a cohort that included permanents residents newly arrived in Ontario using data from Citizenship and Immigration Canada (CIC) data sets. The first data set contained demographic and immigration records on each of the 1192870 new permanent residents who arrived in Ontario during the 10-year period from Jan. 1, 2002, to Dec. 31, 2011. This data set contained the records of every permanent resident lawfully immigrating directly to Ontario.

Using first and last name, sex, date of birth and an administrative application number, we linked 944375 of these records to a second CIC data set containing the preimmigration medical examination results of all applicants seeking temporary or permanent residency in Ontario from 2000 to 2011. Although the results of preimmigration medical examinations are valid for 1 year, we included 2 years of previous data to maximize linkages with our permanent resident data set. Subsets of the 944375 permanent residents in our cohort were then included in analyses to address specific questions.

St. Michael's Hospital Research Ethics Board approved the study.
Preimmigration screening (2008-2011)

Data from CIC on patients with active TB detected through preimmigration screening became available in 2008. We compared rates of active TB detected among the 357085 prospective permanent residents to Ontario and the 334319 permanent residents who actually settled in Ontario between Jan. 1, 2008, and Dec. 31, 2011. We then identified which birth countries accounted for the largest proportion of all immigrants with active TB.

\section{Postimmigration surveillance (2002-2011)}

We linked the 944375 records from our permanent resident cohort with the Ontario Ministry of Health and Long-Term Care's reportable disease database from Jan. 1, 2002, to Dec. 31, 2011, using first and last name, sex, date of birth, country of birth and date of arrival in Canada. Because TB is a reportable disease under provincial law, clinicians and laboratories must report all microbiologically confirmed or clinically diagnosed cases of the disease. Between 2002 and 2011, the Ontario Ministry of Health and Long-Term Care received records for 5835 patients with active TB among people born abroad (i.e., including permanent residents, temporary residents, international visitors and undocumented immigrants).

Using this linked data set, we calculated 2-year incidence rates of active TB detected among permanent residents who were referred for and compliant with postimmigration surveillance, those who were referred and not compliant, and those who were not referred. We also identified which birth countries accounted for the largest proportion of all active TB cases detected among immigrants. We then calculated the number of preimmigration medical examinations needed to detect a single patient with active (pulmonary) TB (because preimmigration screening emphasizes detection of communicable TB), and the number of preimmigration medical examinations and postimmigration surveillance referrals needed to detect a single patient with active TB (all sites) within 2 years of immigration. These analyses were stratified by immigrants' country of birth (see Appendix 2, available at www.cmaj.ca/lookup/suppl/doi :10.1503/cmaj.150011/-/DC1).

\section{Outcomes}

For all permanent residents in whom active TB developed, we calculated the time to diagnosis relative to the time of immigration. Because many domestic applicants live in Canada for years before applying for permanent residency, we created separate plots for overseas and 
domestic applicants, and distinguished TB diagnosed through postimmigration surveillance with TB that was not. In addition, we determined predictors of active TB among new permanent residents and the effect of postimmigration surveillance on the overall burden of TB in Ontario among patients born abroad.

\section{Statistical analysis}

\section{Predictors of active tuberculosis}

We used multivariable Cox proportional hazards regression to identify predictors of active pulmonary or extrapulmonary TB $(n=980$ patients from 2002-2011) among new permanent residents. We restricted our analysis to involve only those residents 11 years of age and older $(n=$ 796033 ), because chest radiographs are not routinely done as part of the preimmigration medical for younger children. Potential predictors included age, sex, marital status, education, English language proficiency, World Health Organization (WHO) incidence of active TB (all sites) in the resident's birth country, immigration category (e.g., refugees, live-in caregivers), location of application for permanent residency (i.e., overseas versus in-Canada), immunosuppression (defined as HIV infection, chronic renal failure or diabetes mellitus) and CIC referral for postimmigration surveillance.

We included covariates in the model using backward selection if they were significant at $p<$ 0.1 . We tested the proportional hazards assumption with plots of scaled Schoenfeld residuals for each covariate over survival time. We plotted Martingale residuals against the incidence rate of TB in the birth country for all observations, while using locally weighted scatter plot smoothing to assess linearity. Because the "referral for medical surveillance" covariate showed large residuals in the first year of immigration, we created a categorical time-dependent covariate representing the effect of postimmigration surveillance in the first year of residency to address this nonproportionality.

\section{Domestic impact of postimmigration surveillance on active tuberculosis in patients born abroad}

We estimated the potential and actual effect of postimmigration surveillance of permanent residents in Ontario on the overall provincial burden of active TB among patients born abroad. To do this, we analyzed data from 3962 people born abroad whose active TB was diagnosed in Ontario between 2005 and 2011. We restricted our analysis to this subgroup because we assumed that no permanent residents arriving in
Ontario before 2002 would remain on surveillance as of 2005 (i.e., most patients undergoing postimmigration surveillance are followed no more than 2 years).

We determined the following factors for each person born abroad who had active TB: their immigration status (i.e., to identify whether they would have required a preimmigration medical); whether they were referred for and complied with postimmigration surveillance; whether their diagnosis was established through postimmigration surveillance; their dates of disease onset and diagnosis; and their anatomic site(s) of disease. Disease onset was defined as the date when symptoms of TB were first reported by a patient. For asymptomatic patients, we used the date on which the first specimen that confirmed the diagnosis of TB was collected.

We defined cases of active TB that would have been potentially detectable through postimmigration surveillance as cases in patients who were referred for surveillance and who were diagnosed with active TB within 2 years of permanent residency. We then compared these cases with those that were actually detected through postimmigration surveillance as reported by Public Health Ontario. We compared the mean (using analysis of variance) and median times from disease onset to diagnosis among patients who were referred for and compliant with surveillance, referred for and noncompliant with surveillance and not referred for surveillance.

We performed all statistical analyses using SAS version 9.2 (SAS Institute, Cary, NC).

\section{Results}

\section{Preimmigration screening}

Of the 357085 preimmigration medical examinations performed on applicants who sought temporary or permanent residency in Ontario between 2008 and 2011, 380 cases of active pulmonary TB were identified (106.4 cases per 100000 medicals). Of the 334319 permanent residents who actually settled in Ontario between 2008 and 2011, 157 cases of active pulmonary TB were identified (47.0 cases per 100000 medicals; Table 1). Twenty-two birth countries accounted for all 157 cases, with $87.3 \%$ of cases occurring in patients who originated from Afghanistan, China, India, Pakistan, the Philippines, and Vietnam (Appendix 2).

\section{Postimmigration surveillance}

From the 944375 preimmigration medicals performed among new permanent residents to Ontario between 2002 and 2011, 22391 postimmigration surveillance referrals were made by 
Table 1: Cases of tuberculosis detected through preimmigration screening (2008-2011) and postimmigration surveillance (20022011), by region

\begin{tabular}{|c|c|c|c|c|c|c|c|c|c|c|c|}
\hline \multirow[b]{2}{*}{ Measure } & \multicolumn{11}{|c|}{ Region of origin } \\
\hline & USA & $\begin{array}{l}\text { Australia } \\
\text { and } \\
\text { New } \\
\text { Zealand }\end{array}$ & $\begin{array}{l}\text { Western } \\
\text { Europe }\end{array}$ & $\begin{array}{l}\text { Middle } \\
\text { East and } \\
\text { North } \\
\text { Africa }\end{array}$ & $\begin{array}{l}\text { Pacific } \\
\text { Islands }\end{array}$ & $\begin{array}{l}\text { Latin } \\
\text { America } \\
\text { and } \\
\text { Caribbean }\end{array}$ & $\begin{array}{c}\text { Eastern } \\
\text { Europe } \\
\text { and } \\
\text { Central } \\
\text { Asia }\end{array}$ & East Asia & $\begin{array}{l}\text { South } \\
\text { Asia }\end{array}$ & $\begin{array}{l}\text { Sub- } \\
\text { Saharan } \\
\text { Africa }\end{array}$ & Total \\
\hline Incidence rate* & 5.5 & 6.9 & 13.3 & 27.4 & 48.0 & 49.7 & 104.2 & 160.8 & 198.5 & 292.8 & 137.0 \\
\hline \multicolumn{12}{|l|}{$\begin{array}{l}\text { Preimmigration screening } \\
(2008-2011)\end{array}$} \\
\hline $\begin{array}{l}\text { No. of preimmigration } \\
\text { medicalst }\end{array}$ & 11224 & 1063 & 15612 & 47427 & 79 & 38967 & 22530 & 84498 & 91547 & 21372 & 334319 \\
\hline $\begin{array}{l}\text { No. of cases (pulmonary) } \\
\text { detected }\end{array}$ & 0 & 0 & 0 & 2 & 0 & 1 & 2 & 85 & 61 & 6 & 157 \\
\hline $\begin{array}{l}\text { No. of preimmigration } \\
\text { medicals per case } \\
\text { (pulmonary) detected }\end{array}$ & NA & NA & NA & 23714 & NA & 38967 & 11265 & 994 & 1501 & 3562 & 2129 \\
\hline \multicolumn{12}{|l|}{$\begin{array}{l}\text { Postimmigration surveillance } \\
\text { (2002-2011) }\end{array}$} \\
\hline $\begin{array}{l}\text { No. of preimmigration } \\
\text { medicals } \neq\end{array}$ & 28501 & 2605 & 35886 & 113093 & 303 & 97646 & 86960 & 236740 & 283016 & 59625 & 944375 \\
\hline $\begin{array}{l}\text { No. of postimmigration } \\
\text { surveillance referrals }\end{array}$ & 127 & 11 & 317 & 875 & 2 & 998 & 2249 & 10196 & 6256 & 1360 & 22391 \\
\hline $\begin{array}{l}\text { No. of preimmigration } \\
\text { medicals per surveillance } \\
\text { referral }\end{array}$ & 224.4 & 236.8 & 113.2 & 129.2 & 151.5 & 97.8 & 38.7 & 23.2 & 45.2 & 43.8 & 42.2 \\
\hline $\begin{array}{l}\text { No. of patients who } \\
\text { complied with surveillance }\end{array}$ & 91 & 8 & 172 & 490 & 0 & 653 & 1098 & 6315 & 3724 & 836 & 13387 \\
\hline $\begin{array}{l}\text { No. of cases (all sites) } \\
\text { detected within } 2 \text { yr of } \\
\text { immigration }\end{array}$ & 0 & 0 & 0 & 4 & 0 & 11 & 16 & 156 & 214 & 101 & 502 \\
\hline $\begin{array}{l}\text { No. of cases (all sites) } \\
\text { potentially detectable§ } \\
\text { through surveillance }\end{array}$ & 0 & 0 & 0 & 3 & 0 & 2 & 5 & 67 & 74 & 17 & 168 \\
\hline $\begin{array}{l}\text { No. of cases (all sites) } \\
\text { actually detected through } \\
\text { surveillance }\end{array}$ & 0 & 0 & 0 & 3 & 0 & 2 & 4 & 46 & 38 & 9 & 102 \\
\hline $\begin{array}{l}\text { No. of preimmigration } \\
\text { medicals per potentially } \\
\text { detectable§ case }\end{array}$ & NA & NA & NA & 37698 & NA & 48823 & 17392 & 3533 & 3825 & 3507 & 5621 \\
\hline $\begin{array}{l}\text { No. of preimmigration } \\
\text { medicals per actually detected } \\
\text { case }\end{array}$ & NA & NA & NA & 37698 & NA & 48823 & 21740 & 5147 & 7448 & 6625 & 9259 \\
\hline $\begin{array}{l}\text { No. of postimmigration } \\
\text { surveillance referrals per } \\
\text { potentially detectable§ case }\end{array}$ & NA & NA & NA & 291.7 & NA & 499.0 & 449.8 & 152.2 & 84.5 & 80.0 & 133.3 \\
\hline $\begin{array}{l}\text { No. of postimmigration } \\
\text { surveillance referrals per } \\
\text { actually detected case }\end{array}$ & NA & NA & NA & 291.7 & NA & 499.0 & 562.3 & 221.7 & 164.6 & 151.1 & 219.5 \\
\hline \multicolumn{12}{|c|}{$\begin{array}{l}\text { Note: NA = undefined values where no cases were detected. } \\
\text { *Calculated by weighting the World Health Organization-reported national tuberculosis incidence rate for each birth country in the year of immigration by the } \\
\text { corresponding number of immigrants. } \\
\text { †Outcome data for preimmigration screening reflect the period between } 2008 \text { and } 2011 \text { ( } n=334319 \text { medicals given to people who became permanent } \\
\text { residents). Given the purpose of preimmigration screening to detect communicable diseases, only pulmonary tuberculosis cases were reported. } \\
\neq \text { Outcome data for postimmigration surveillance reflect the period between } 2002 \text { and } 2011 \text { ( } n=944375 \text { medicals given to people who became permanent } \\
\text { residents). } \\
\text { §Potentially detectable tuberculosis was defined as active disease developing at any site within } 2 \text { years of immigration among people who were referred to } \\
\text { postimmigration surveillance. }\end{array}$} \\
\hline
\end{tabular}


CIC (2.4\% of all medicals; Table 1$)$. Ratios of preimmigration medicals to surveillance referrals ranged from 23:1 among residents born in East Asia to 237:1 among those born in Australia and New Zealand (Table 1).

Among these 944375 new permanent residents, active TB developed in 502 residents from 35 birth countries within 2 years of residency (2-yr inci- dence of 53 cases per 100000 persons). Of the 921984 residents who were not referred for surveillance, active TB developed in 334 people (2-yr incidence of 36 cases per 100000 persons). Among the 13387 who were referred for and complied with surveillance, active TB developed in 102 people (2-yr incidence of 762 per 100000 persons); of the 9004 individuals who did not comply with sur-

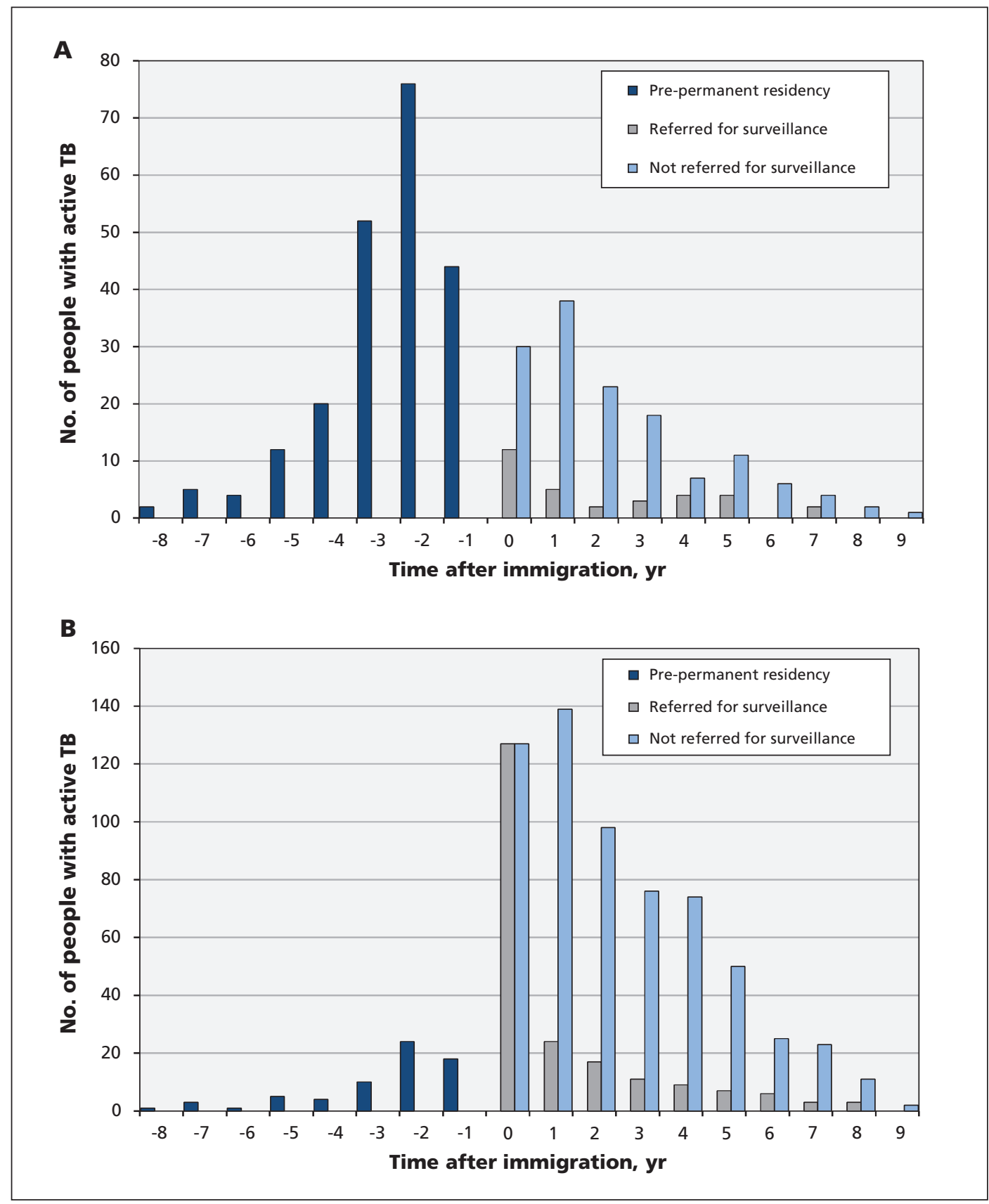

Figure 1: Onset of active tuberculosis (TB) relative to time of immigration among applicants for permanent residency (A) from within Canada and (B) overseas, 2002-2011. Bars with negative time values represent TB cases reported among people born abroad before they became permanent residents $(55.6 \%$ of patients among in-Canada applicants). Among overseas applicants, bars with negative time values represent temporary residents, visitors and other people born abroad in whom active TB developed while in Ontario, who then left Canada, applied for permanent residency overseas and subsequently returned to become permanent residents in Ontario. Bars with positive time values represent TB cases among permanent residents stratified by whether they were referred for postimmigration surveillance. 
veillance, active TB developed in 66 people (2-yr incidence of 733 per 100000 persons).

The number of preimmigration medicals performed per case of active TB detected through postimmigration surveillance ranged from 5147 among immigrants born in East Asia to 48823 among immigrants born in Latin America and the Caribbean. No cases of active TB were reported among immigrants born in Australia, New Zealand, the Pacific Islands, the US or Western Europe. The number of surveillance referrals per TB case detected though postimmigration surveillance ranged from 151 among immigrants born in Sub-Saharan Africa to 562 among those born in Eastern Europe and Central Asia.

Table 2: Predictors of postimmigration active tuberculosis at any site among permanent residents 11 years of age and older, 2002-2011

\begin{tabular}{|c|c|}
\hline Predictor & $\mathrm{HR}(95 \% \mathrm{Cl})$ \\
\hline \multicolumn{2}{|l|}{ Postimmigration surveillance referral* } \\
\hline Not referred & 1.00 \\
\hline Referred, baseline hazard & $4.68(3.76-5.82)$ \\
\hline $\begin{array}{l}\text { Referred, additional hazard during first year } \\
\text { of immigration }\end{array}$ & $5.69(4.16-7.79)$ \\
\hline \multicolumn{2}{|l|}{ Tuberculosis incidence in country of birth } \\
\hline 0-30 (reference) & 1.00 \\
\hline$>30-100$ & $3.72(2.29-6.06)$ \\
\hline$>100-200$ & $6.27(3.90-10.07)$ \\
\hline$>200$ & $13.65(8.64-21.57)$ \\
\hline \multicolumn{2}{|l|}{ Immigration category $\ddagger$} \\
\hline Live-in caregiver & $4.15(3.51-4.90)$ \\
\hline Refugee & $2.46(1.87-3.25)$ \\
\hline Other (reference) & 1.00 \\
\hline \multicolumn{2}{|l|}{ Age at immigration, yr§ } \\
\hline $11-35$ & $1.30(1.13-1.50)$ \\
\hline > 35-65 (reference) & 1.00 \\
\hline$>65$ & $1.36(1.05-1.74)$ \\
\hline Application for residency in Canadaף & $0.39(0.32-0.47)$ \\
\hline Immunocompromised** & $1.75(1.30-2.36)$ \\
\hline \multicolumn{2}{|c|}{ 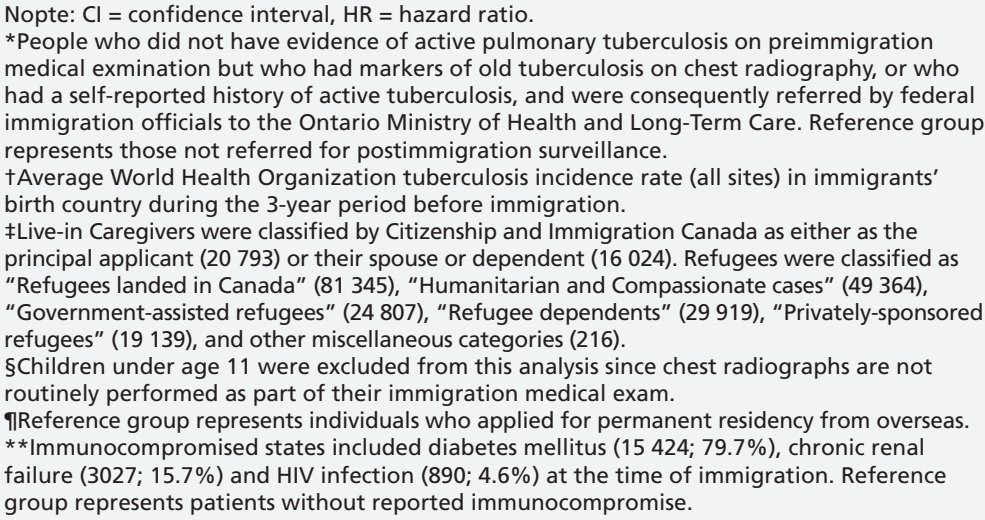 } \\
\hline
\end{tabular}

\section{Time to diagnosis}

Among applicants for permanent residency from within Canada, $55.6 \%$ of those with active TB were diagnosed with it before they received their residency status (Figure 1A). Among overseas applicants who had active TB, $28.3 \%$ were diagnosed with it during the first year of permanent residency; $50.0 \%$ of those applicants had been referred for surveillance (see Figure 1B). After the first year of residency, $13.8 \%$ of reported cases of active TB were among people who had been referred for surveillance.

\section{Predictors of active tuberculosis}

We identified 6 independent predictors of active TB postimmigration: referral for postimmigration surveillance, incidence rate of TB in the country of birth, immigration category, site of application for permanent residency, immune status and age (Table 2). Inspection of Martingale residual plots from our model did not show nonlinearity.

\section{Domestic impact on active tuberculosis in patients born abroad}

Of the 3962 patients born abroad who had TB that was reported in Ontario between 2005 and $2011,163(4.1 \%)$ and $103(2.6 \%)$ were potentially detectable and actually detected through post-immigration surveillance, respectively (Figure 2). Among the cases that were readily detectable through postimmigration medical assessment (e.g., chest radiography showing signs of pulmonary or pleural TB or intrathoracic lymphadenitis, or peripheral lymphadenitis apparent on physical examination), we found differences in times from symptom onset to diagnosis. Permanent residents referred for and compliant with surveillance had the shortest times to diagnosis (mean $47.0 \mathrm{~d}$, median $21 \mathrm{~d}$ ) relative to both those referred who did not comply with surveillance (mean $83.8 \mathrm{~d}$, median $39 \mathrm{~d}$ ) and those who were not referred at all (mean $73.2 \mathrm{~d}$, median $39 \mathrm{~d}$ ). These differences were significant between immigrants who were referred for and compliant with surveillance and those who were referred and noncompliant ( $p=0.006)$, as well as between those who were referred and compliant and those who were not referred $(p=0.03)$. However, there was no significant difference in time to diagnosis between the immigrants who were referred and not compliant and the immigrants who were not referred $(p=0.74)$.

\section{Interpretation}

New immigrants arrived in Ontario from 214 countries during the study period, but all cases of active TB detected through preimmigration 
screening or postimmigration surveillance occurred in patients who originated from just 35 countries. Our findings highlight the inefficiency of universal screening for TB among new immigrants independent of the incidence of disease in their countries of origin. Furthermore, although immigrants are selected for postimmigration surveillance based solely on the findings of chest radiography and self-reported history, we found several other strong predictors of active TB, most notably the incidence of the disease in the country of birth. Moreover, only 1 in 40 cases reported in Ontario in patients born abroad were actually detected through postimmigration surveillance. These cases were detected about 18 days earlier than cases in patients not undergoing postimmigration surveillance.

More than 1 million immigrants to Canada, Australia, France, New Zealand and the United States, collectively, undergo screening for TB

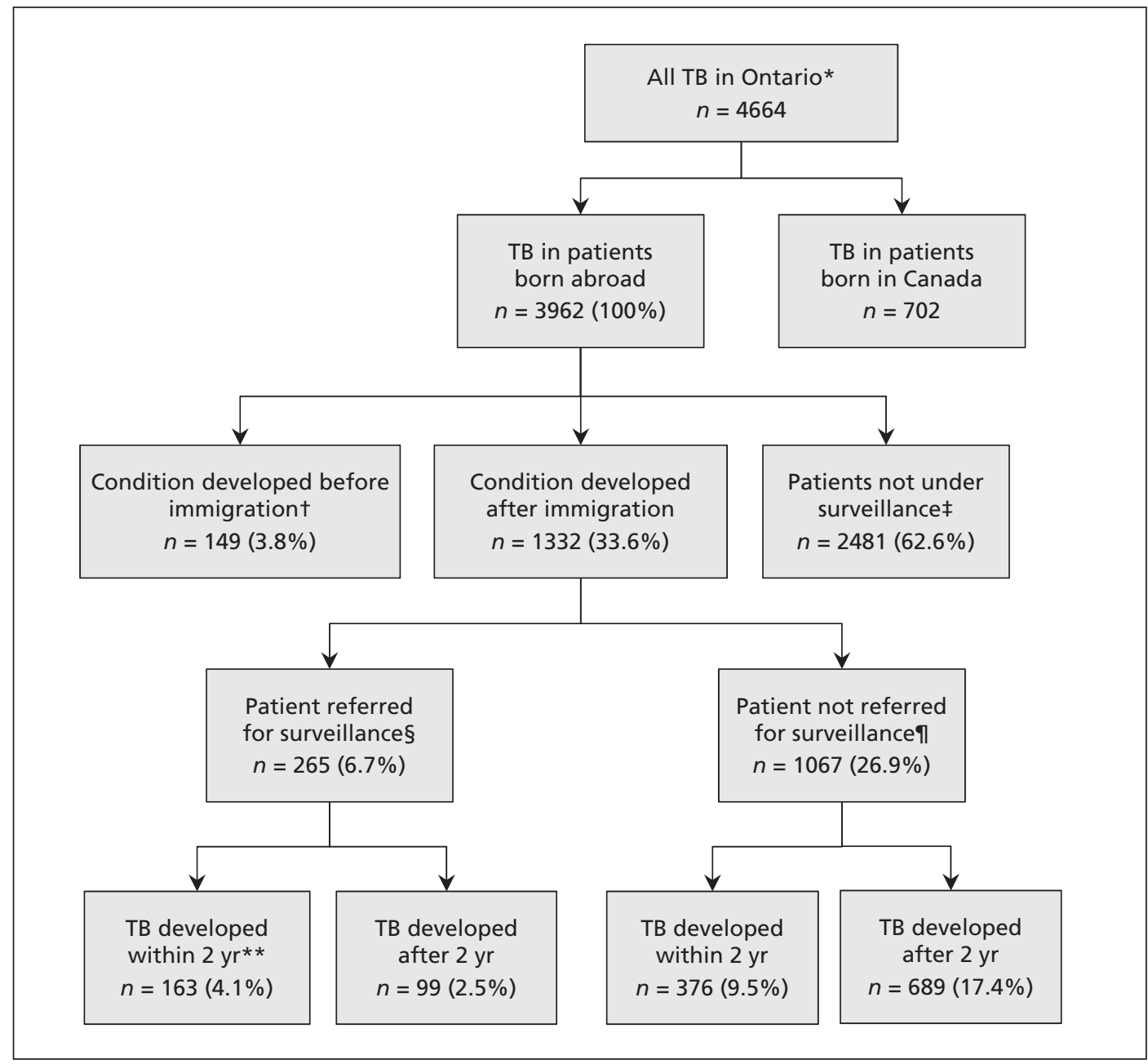

Figure 2: Proportion of people in Ontario with active tuberculosis (TB) that was potentially detectable through postimmigration surveillance, 2005-2011. *Includes all cases among residents born in Canada and those born abroad that were reported to the Ontario Ministry of Health and Long-Term Care from 20052011. People born abroad include permanent residents, temporary residents, visitors and undocumented immigrants. Percentages reflect the proportion of all active TB cases among people born abroad. Percentages may not sum to 100 owing to the rounding of values. TPatients in whom active TB developed before immigration include those who received their diagnosis in Ontario but were not permanent residents at the time (e.g., temporary visitors). These cases $(n=149)$ would not have been detectable through postimmigration surveillance. IIncludes Ontario residents who received permanent residency status at least 3 years earlier (i.e., before 2002) and hence would not likely have undergone postimmigration surveillance as of 2005, temporary visitors who would not have had a preimmigration medical, and undocumented immigrants or other visitors to Canada who would not have had a preimmigration medical. These cases $(n=2481)$ would not have been detectable through postimmigration surveillance. §Time to development of active TB unknown for 3 patients. ๆTime to development of active TB unknown for 2 patients. **Includes cases of active TB that would have been potentially detectable through postimmigration surveillance of permanent residents. Of the cases that developed within 2 years of the patient's immigration $(n=163), 155$ may have been detectable on chest radiography (pulmonary, pleural or intrathoracic lymphadenitis) or peripheral lymph node examination, and $103(2.6 \%)$ were actually detected through postimmigration surveillance. 
each year; however, our understanding of the impact of this screening is limited..$^{20} \mathrm{~A}$ recent large-scale study of US-bound immigrants and refugees identified high rates of smear-negative pulmonary TB (i.e., 3 negative smears with chest radiographic markers suggestive of active TB) on overseas screening, with most cases identified in immigrants from a short list of high-incidence countries. ${ }^{21}$ Our analysis complements those findings, in that our primary outcome is active TB confirmed through culture, our study period includes up to 10 years' postimmigration followup and we identify person-level risk factors for the future development and timing of active TB. Furthermore, our study differentiates TB risks between overseas and domestic applicants for permanent residency, describes outcomes of TB screening by country of birth and quantifies the potential and actual impact of postimmigration surveillance on the domestic burden of active TB in patients born abroad.

\section{Limitations}

Because no systematic recording of test results for latent TB infection or completed treatment exists in Ontario, we were unable to account for the potential impact of treatment of latent infection identified through immigration screening. However, the permanent residents who were referred for and complied with postimmigration surveillance could have reduced their future risk of developing active TB if they had undergone testing and had been found to have latent TB infection, deemed eligible for and offered treatment and then completed treatment. Numerous studies have shown that fewer than $15 \%$ of immigrants at risk for latent TB infection ultimately complete preventive therapy, even in specialized clinical settings. ${ }^{22-25}$ Although we were unable to quantify the population-level impact of treating latent infection on active TB in our study, it was probably limited.

We assumed that immigrants settling in Ontario remained in the province for the duration of the study period. This assumption could have confounded our results if interprovincial or interterritorial resettlement patterns in Canada are associated with risk of active TB within 2 years of immigration. In addition, we were unable to access immigration medical records (to determine postimmigration referral status) for immigrants who first settled in another province and subsequently moved to Ontario.

Although postimmigration surveillance may detect patients with active TB before their symptoms develop, we were unable to compare the number of immigrants who were asymptomatic among those who were referred for and compli- ant with surveillance, those who were referred for and noncompliant with surveillance and those who were not referred for surveillance.

\section{Conclusion}

Programs screening for active TB in immigrants from low-incidence countries incurs substantial costs to the federal government, the provincial and territorial ministries of health, local health authorities, medical providers and the immigrants themselves without showing evidence of substantial public health benefit. Hence, we believe that this practice should be discontinued. The United Kingdom has recently rolled out a policy focusing its preimmigration screening efforts on 67 high-incidence countries. ${ }^{26}$

Among immigrants who do undergo screening, the criteria for referral for postimmigration surveillance should be revised to include additional predictors of active TB beyond chest radiography, such as the incidence rate of TB in the country of birth, immigration category, site of application for permanent residency, immune status and age. These data are currently collected on all new immigrants to Canada.

Postimmigration surveillance presents a special opportunity for clinicians to offer treatment for latent TB infection to patients at high-risk and should be encouraged. ${ }^{27,28}$ Among overseas applicants who are ineligible for, or choose not to receive, treatment, postimmigration surveillance can be limited to 1 year or less in most circumstances. Furthermore, postimmigration surveillance for domestic applicants (i.e., applicants who would have had a preimmigration medical in Canada in the previous year) is largely redundant and should be discontinued.

The modest yields of immigration-related screening for TB highlights why major immigrant-receiving countries should consider greater investments in global TB prevention and control as a means to protect their own domestic health and economic interests. ${ }^{29}$ Because Australia, France, New Zealand and the United States have very similar practices to Canada in terms of screening for TB in new immigrants, lessons learned from this study could have important policy implications for other major immigrantreceiving countries. ${ }^{30,31}$

\section{References}

1. Gushulak BD, MacPherson DW. Globalization of infectious diseases: the impact of migration. Clin Infect Dis 2004;38:1742-8.

2. Langlois-Klassen D, Wooldrage KM, Manfreda J, et al. Piecing the puzzle together: foreign-born tuberculosis in an immigrantreceiving country. Eur Respir J 2011;38:895-902.

3. Enarson D, Ashley MJ, Grzybowski S. Tuberculosis in immigrants to Canada. A study of present-day patterns in relation to immigration trends and birthplace. Am Rev Respir Dis 1979;119:11.

4. Tuberculosis among the foreign-born in Canada. Can Commun Dis Rep 2003;29:10-6. 
5. Cain KP, Benoit SR, Winston CA, et al. Tuberculosis among foreign-born persons in the United States. JAMA 2008;300: 405-12.

6. Long R, Sutherland K, Kunimoto D, et al. The epidemiology of tuberculosis among foreign-born persons in Alberta, Canada, 19891998: identification of high risk groups. Int J Tuberc Lung Dis 2002;6:615-21.

7. Menzies HJ, Winston CA, Holtz TH, et al. Epidemiology of tuberculosis among US- and foreign-born children and adolescents in the United States, 1994-2007. Am J Public Health 2010; 100:1724-9.

8. Medical exam requirements for permanent residents. Ottawa: Citizenship and Immigration Canada; 2012. Available: www.cic.gc. $\mathrm{ca} /$ english/information/medical/medexams-perm.asp (accessed 2013 Feb.1).

9. Canadian tuberculosis standards. 7th ed. Ottawa: Canadian Thoracic Society; 2013.

10. Canadian Tuberculosis Committee, Canadian Thoracic Society Canadian guidelines for the investigation and follow-up of individuals under medical surveillance for tuberculosis after arrival in Canada. Can Commun Dis Rep 2001;27:157-65.

11. Richards B, Kozak R, Brassard P, et al. Tuberculosis surveillance among new immigrants in Montreal. Int J Tuberc Lung Dis 2005; 9:858-64.

12. Uppaluri A, Naus M, Heywood N, et al. Effectiveness of the Immigration Medical Surveillance Program for tuberculosis in Ontario. Can J Public Health 2002;93:88-91.

13. Wobeser WL, Yuan L, Naus M, et al. Expanding the epidemiologic profile: risk factors for active tuberculosis in people immigrating to Ontario. CMAJ 2000;163:823-8.

14. Wobeser W, Naus M, Brunton J, et al. TB surveillance in Canada. Can J Public Health 2002:93:317.

15. Creatore MI, Lam M, Wobeser WL. Patterns of tuberculosis risk over time among recent immigrants to Ontario, Canada. Int $J$ Tuberc Lung Dis 2005;9:667-72.

16. Orr PH, Manfreda J, Hershfield ES. Tuberculosis surveillance in immigrants to Manitoba. CMAJ 1990;142:453-8.

17. Tuberculosis in Canada. Ottawa: Public Health Agency of Canada; 2014. Available: www.phac-aspc.gc.ca/tbpc-latb/pubs/ tbcan13pre/index-eng.php (accessed 2015 July 9).

18. Population and dwelling counts, for Canada, provinces and territories, census metropolitan areas and census. Ottawa: Statistics Canada; 2012. Cat. no. 98-310-XWE2011002. Available: www5.statcan .gc.ca/olc-cel/olc.action?objId=98-310-2011002\&objType=46\&lang $=$ en\&limit $=0$ ).

19. Facts and figures. Immigration overview: permanent and temporary residents. Ottawa: Citizenship and Immigration Canada; 2012.

20. Pareek M, Baussano I, Abubakar I, et al. Evaluation of immigrant tuberculosis screening in industrialized countries. Emerg Infect Dis 2012;18:1422-9.

21. Liu Y, Weinberg MS, Ortega LS, et al. Overseas screening for tuberculosis in US-bound immigrants and refugees. $N$ Engl J Med 2009;360:2406-15.

22. Levesque J-F, Dongier P, Brassard P, et al. Acceptance of screening and completion of treatment for latent tuberculosis infection among refugee claimants in Canada. Int J Tuberc Lung Dis 2004;8:711-7.

23. Adhikari N, Menzies R. Community-based tuberculin screening in Montreal: a cost-outcome description. Am J Public Health 1995;85:786-90.

24. Blum RN, Polish LB, Tapy JM, et al. Results of screening for tuberculosis in foreign-born persons applying for adjustment of immigration status. Chest 1993;103:1670-4.
25. Yuan L, Richardson E, Kendall PRW. Evaluation of a tuberculosisscreening program for high-risk students in Toronto schools. CMAJ 1995; 153:925-32.

26. New phase of tuberculosis screening launched as part of immigration rules changes. London (UK): Home Office; 2013 Available: www.gov.uk/government/news/new-phase-of-tuberculosis-screening-launched-as-part-of-immigration-rules-changes

27. Greenaway C, Sandoe A, Vissandjee B, et al. Tuberculosis: evidence review for newly arriving immigrants and refugees. CMAJ 2011;183:E939-51.

28. Khan K, Muennig P, Behta M, et al. Global drug-resistance patterns and the management of latent tuberculosis infection in immigrants to the United States. N Engl J Med 2002;347:1850-9.

29. Schwartzman K, Oxlade O, Barr RG, et al. Domestic returns from investment in the control of tuberculosis in other countries. N Engl J Med 2005;353:1008-20.

30. Pang SC, Harrison RH, Brearley J, et al. Tuberculosis surveillance in immigrants through health undertakings in Western Australia. Int J Tuberc Lung Dis 2000;4:232-6.

31. Alvarez GG, Gushulak B, Abu RK, et al. A comparative examination of tuberculosis immigration medical screening programs from selected countries with high immigration and low tuberculosis incidence rates. BMC Infect Dis 2011;11.

Affiliations: Department of Medicine (Khan, Gardam), Division of Infectious Diseases, University of Toronto; Centre for Research on Inner City Health (Khan, Miniota, Creatore, Chan, Hu, Wang), Li Ka Shing Knowledge Institute, St. Michael's Hospital, Toronto, Ont.; Public Health and Preventive Medicine Residency Program (Hirji), Department of Clinical Epidemiology and Biostatistics, McMaster University, Hamilton, Ont.; Infection Prevention and Control (Gardam), University Health Network; Faculty of Medicine (Rawal), University of Toronto, Toronto, Ont.; Faculty of Medicine (Ellis), University of Ottawa, Ottawa, Ont.; Toronto Public Health and Dalla Lana School of Public Health (Rea), University of Toronto, Toronto, Ont

Contributors: Kamran Khan led the study from its initial design to the preparation of the first and last drafts of the manuscript. Mustafa Hirji, Jennifer Miniota, Michael Gardam and Elizabeth Rea contributed to the design and analysis of the study, in addition to the preparation of and edits to the final version of the manuscript. Mustafa Hirji, Wei Hu and Jun Wang performed all statistical analyses and helped prepare the final version of the manuscript. Sameer Rawal, Edward Ellis, Angie Chan and Maria Creatore made substantial content contributions and edits to the final manuscript. All of the authors approved the final version to be published and agree to act as guarantors of the work.

Funding: This study was funded by the Ontario Ministry of Health and Long-Term Care and the Canadian Institutes of Health Research with in-kind support from Citizenship and Immigration Canada and Public Health Ontario. The views and opinions expressed in this publication are those of the authors and are not necessarily endorsed by Citizenship and Immigration Canada or the Ontario Ministry of Health and Long-Term Care. 